\title{
Aprendizagem significativa sobre polímeros a partir de experimentação e problematização
}

\author{
Meaningful learning on polymers from experimentation and \\ problematization
}

\author{
Graziane Gomes dos Santos ${ }^{1}$ \\ Tiago Nery Ribeiro ${ }^{2}$ \\ Divanizia do Nascimento Souza ${ }^{3}$
}

\section{Resumo}

Neste estudo investigamos sobre a aprendizagem de alunos da terceira série do ensino médio em aulas de química por meio atividades relacionadas ao conteúdo Polímeros em uma Sequência Didática (SD). A metodologia utilizada empregou abordagem do tipo qualitativa, utilizando alguns elementos de análise textual discursiva, fundamentada em atividades experimentais. Os alunos participantes da pesquisa formaram dois grupos, sendo um composto por alunos de uma escola da rede privada e outros de uma escola da rede pública de ensino. Inicialmente foram investigados os conhecimentos prévios dos alunos sobre o conteúdo em questão, com base na Teoria da Aprendizagem Significativa. Em seguida, as atividades da sequência didática foram desenvolvidas e se procedeu à análise dos discursos dos alunos por meio das respostas a questionamentos. As estratégias utilizadas se mostraram motivadoras e serviram como organizadores prévios para os subsunçores. À medida que os subsunçores tornaram-se mais elaborados foi possível aos alunos compreender informações novas e aprender significativamente. Nesse contexto, podemos considerar que as atividades da SD se relacionaram com os conceitos sobre polímeros já existentes na estrutura cognitiva de cada aluno.

Palavras chave: sequência didática (SD); aprendizagem significativa; polímeros.

\section{Abstract}

The aim of this study was to investigate on the learning of students in senior high school chemistry classes during activities related to the subject polymers in a didactic sequence (SD). We decided to explore the data from a qualitative type approach, employing some aspects of discursive textual analysis, based on experimental activities. The students participating in the research formed two groups, one from a private school and another from a public school. First, the students' prior knowledge on the subject was investigated,

\footnotetext{
${ }^{1}$ Universidade Federal de Sergipe | grazianequimica@gmail.com

${ }^{2}$ Universidade Federal de Sergipe | tnribeiro@globo.com

${ }^{3}$ Universidade Federal de Sergipe | divanizia@gmail.com
} 
based on Meaningful Learning Theory. Then, the activities of the didactic sequence (DS) were developed and the students' discourses were analyzed based on the answers to questions. The strategies used were motivating and served as advanced organizers for the subsuming concepts. As the subsuming concepts became more elaborate, the students were able to understand new information and learn significantly. In this context, we can consider that the activities of DS related to the concepts about polymers already existing in the student's cognitive structure.

Keywords: didactic sequence (DS); meaningful learning; polymers.

\section{Introdução}

É evidente que o ensino de Química na Educação Básica ainda privilegia práticas tradicionais, sendo repleto de representações químicas e fórmulas que devem ser memorizadas pelos estudantes. Conforme afirma Chassot (2004, p. 29), a prática de um modelo tradicional de ensino nos leva a "concordar com a hipótese de que nosso ensino de química, pelo menos em nível médio, é - literalmente - inútil. Isto é, mesmo se não existisse, muito pouco (ou nada) seria diferente." Diversos motivos podem justificar as condições limitantes das práticas de ensino de Química no Ensino Médio. Um apontado por Santos (2017) é o extenso currículo da disciplina. Para cumprir os programas propostos, os professores tendem a aligeirar as explicações, privando os estudantes de situações de intercâmbios com seus professores. Muito provavelmente, essas condições são algumas das razões para os alunos não conseguirem perceber a relação dessa disciplina com o cotidiano. Por isso, com frequência, ouve-se na escola alunos questionarem sobre porque devem aprender tantos conceitos químicos se, na maioria das vezes, não saberão utilizá-los numa futura profissão. Esse tipo de questionamento pode permanecer em aberto quando os professores não sabem como responder aos seus alunos, por falta de interesse ou de preparo para lidar com tal questão.

Segundo os Parâmetros Curriculares Nacionais do Ensino Médio, PCNEM (BRASIL, 2002), ensinar Química sob a perspectiva da educação básica é criar possibilidades que auxiliem na compreensão do conteúdo e na construção do conhecimento científico, estreitando as relações entre ambos, considerando suas implicações na sociedade. Logo, entende-se que é preciso utilizar métodos educacionais que possibilitem aos alunos desenvolverem suas capacidades críticas, criativas e investigativas.

A pertinência do ensino sobre um fenômeno químico a partir de uma abordagem cientifica, em uma prática de ensino experimental ou por meio de atividades relacionadas que simulem o fenômeno em questão, tem uma maior significância para a aprendizagem do que a partir de atividades mecânicas (AMARAL, 1996).

O tema Polímeros pode ser considerado como um conteúdo abrangente da Química quando se pondera sobre as aplicações práticas desses materiais nas várias áreas de atividade do ser humano. Quando algumas dessas aplicações são levadas para o ambiente escolar podem servir como ferramenta de enriquecimento para as ações do professor na abordagem de tal conteúdo em sala de aula. Na abordagem desse conteúdo se pode destacar, por exemplo: tipos de polímeros e suas aplicações, reações poliméricas e reciclagem de polímeros.

Ao tratar desse assunto neste artigo, buscamos considerar que, conforme as Orientações Curriculares, o Ensino Médio tem como finalidade assegurar ao aluno a 
formação para o exercício da cidadania (BRASIL, 2006), o que enfatiza a importância de articular os eixos do conhecimento químico com temas sociais. Isso está em consonância com os PCN, que consideram que os conhecimentos abordados no ensino da Química devem auxiliar na construção de uma visão de mundo articulada e menos fragmentada.

Nesta perspectiva, o objetivo central deste estudo foi investigar sobre a aprendizagem de alunos da terceira série do ensino médio sobre o conteúdo Polímeros, a partir do desenvolvimento de uma sequência didática (SD) abordando conceitos e aplicações desse conteúdo.

\section{Aprendizagem Significativa para o Ensino de Química}

Na escola básica, o ensino de Química deve se aproximar do cotidiano do aluno e de seus interesses. Considerando que todos precisem aprender um mínimo de conceitos científicos (MILARÉ et al, 2009), esse ensino, que resulta em alfabetização científica, possibilita conduzir ao aprendizado científico para o exercício da cidadania.

Há quase duas décadas, Hage Junior (1998) considerava que apresentar ao aluno significados sobre os conceitos químicos de polímeros, assim como a importância desses compostos para a sociedade atual, era de suma importância, pois estamos vivendo na era do plástico. Isso é notório quando se repara em toda a aplicabilidade dos diferentes tipos de plásticos, que quimicamente são classificados como polímeros.

Uma teoria que dá suporte à construção de significados sobre conceitos científicos é a Teoria da Aprendizagem Significativa, proposta por David Ausubel. Segundo Moreira (2006), a aprendizagem significativa é apresentada sob duas perspectivas cognitivas, uma a partir da visão clássica, proposta por David Ausubel na década de 1960, e da visão humanística, a partir de estudos de Josef D. Novak e D. Bob Gowin, a partir da década de 1980. "Na visão clássica, aquilo que o aprendiz já sabe é o mais importante fator isolado que influencia a aprendizagem. Naturalmente, então, o ensino deve, essencialmente, ser conduzido de acordo" (MOREIRA, 2006, p. 2). Do ponto de vista humanista, conforme Novak e Gowin, a aprendizagem significativa ocorre quando o aprendiz se encontra disposto para adquirir novas aprendizagens (MOREIRA, 2006).

A cognição ou estrutura cognitiva é responsável pela capacidade que um sujeito tem de reter informações, dados e conceitos, dentre outros atributos de aprendizagem. A cognição de um sujeito o permite poder aprender coisa novas. Para que haja um novo aprendizado se faz necessário que os conceitos expostos possuam significados relacionados com o que o aprendiz já tenha aprendido. Para isso, existe uma condição: a aprendizagem só é classificada como significativa quando o conteúdo aprendido ocorre de maneira não arbitrária e não literal (AUSUBEL, 2003). Cabe ressaltar que aquilo que o aprendiz já sabe pode ser uma ideia ou um pré-requisito, que representa uma predisposição para o recebimento de uma nova informação. A isso Ausubel denominou subsunçor.

Os subsunçores "não são necessariamente conceitos, podem ser ideias, modelos, proposições, representações que servem de 'ancoradouro' para novos conhecimentos" (MOREIRA, 2008, p. 2). Por exemplo, o aluno pode não conhecer conceitos científicos sobre polímeros nem sobre reações de polimerização, tampouco sobre a aplicação tecnológica dos polímeros; contudo, ele pode conhecer conceitos subsunçores do que seja um plástico, pois talvez se preocupe com as consequências ambientais associadas a um copo plástico jogado na rua, por já ter ouvido falar sobre poluição do meio ambiente em decorrência do descarte de plásticos. 
A aprendizagem significativa na perspectiva Ausubeliana tem como foco a aprendizagem sem a utilização de critérios de memorização. Neste sentido, existe uma crítica firme de Ausubel a respeito da aprendizagem mecânica, por considerar que esse tipo de aprendizagem ocorre quando novas informações são aprendidas sem uma interação com os subsunçores existentes na estrutura cognitiva do indivíduo, interagindo com o conteúdo de forma arbitrária e literal (MOREIRA e MASINI, 2006).

Outros dois tipos de aprendizagem são citados por Ausubel: a aprendizagem por recepção e a aprendizagem por descoberta. Embora a aprendizagem por descoberta favoreça uma aprendizagem mecânica, quando o que é aprendido pelo aluno é conduzido na sua forma pronta, ela também pode suscitar uma aprendizagem significativa. Para tanto, é necessário que se tenha uma interação com subsunçores já presentes nos alunos. Assim, a aprendizagem por recepção e a aprendizagem por descoberta não podem ser consideradas por si sós, pois necessitam de observador para afirmar que houve aprendizagem significativa (MOREIRA, 2009).

\section{Condições para ocorrência da aprendizagem significativa}

No contexto de uma sequência didática não se pode afirmar que o conhecimento sobre os materiais produzidos é semelhante ao aprendizado significativo. De acordo com Ausubel (2003, p. 17) "a aprendizagem significativa não é sinônimo de aprendizagem de material significativo. [...]". Num contexto de uma sequência didática as atividades criadas pelo professor são o principal mecanismo de ação para a aprendizagem significativa do aluno; ainda assim, caso o aluno não tenha em sua cognição o componente significativo de aprendizagem, ele pode vir a aprender por memorização num primeiro momento (AUSUBEL, 2003).

A aprendizagem significativa depreende uma nova aquisição ao subsunçor, modificando esta informação nova e o subsunçor que fora necessário para a aprendizagem significativa, isto o torna em um novo subsunçor. Dessa forma, conceitos, ideias e esquemas cognitivos são transformados. Logo, uma sequência didática poderá ser potencialmente significativa, satisfazendo o que Ausubel (2003) preconizou, quando seus materiais representem mecanismos que possibilitem ao aprendiz adquirir aprendizagem significativa.

Quanto à perspectiva interacionista social da aprendizagem significativa, Novak e Gowin (1996) teceram uma relação entre a teoria da aprendizagem significativa clássica com a teoria vygotskyana, considerando que a aprendizagem significativa ocorre através de um compartilhamento de significados entre o material educativo, o professor e o aprendiz (aluno $\leftrightarrow$ professor $\leftrightarrow$ materiais educativos do currículo). O papel do professor, que já está inteirado acerca dos significados da matéria ensinada, é ser o mediador nesta troca de significados.

Assim, tendo como instrumento de análise o material e as condições baseadas na relação existente entre o aluno e a aprendizagem significativa, o resultado será, caso seja possível, a captação das informações pela estrutura cognitiva desse aluno, que serão guardadas de forma significativa. 


\section{Metodologia}

A partir do objetivo definido aqui, e considerando a sequência didática como uma ação ativa que se desenvolve ao longo do processo de ensino e aprendizagem, tem-se que este estudo se enquadra numa abordagem do tipo qualitativa, que utiliza elementos da pesquisa-ação e propõe uma mudança da realidade social. Como afirma Baldissera (2001, p. 25), "na pesquisa-ação acontece simultaneamente o "conhecer" e o "agir", uma relação dialética sobre a realidade social desencadeada pelo processo de pesquisa". Escolhemos o ensino de forma interdisciplinar, considerando que o referencial teórico abordado e as práticas podem levar à conscientização coletiva, a partir dos interesses dos envolvidos na pesquisa.

Enquanto experiência de ensino, uma Sequência Didática (SD) é definida como um procedimento que pode ser discutido e modificado de forma ativa por seus personagens. A SD proposta aqui foi construída a partir de situações baseadas nos conhecimentos prévios dos alunos sobre o tema em questão.

Uma SD pode sofrer algumas alterações a partir da sua prática em sala de aula, para que se alcance uma promoção da aprendizagem significativa dos alunos. A partir da vivência de uma SD, espera-se um maior grau de abstração sobre os conteúdos por parte dos alunos, já que vivenciam etapas, partindo das mais simples para mais complexas, que permitem explorar seus conhecimentos prévios, aprimorando-os.

Com a Teoria da Aprendizagem Significativa podemos definir vários níveis de análise, uma vez que uma SD é avaliada durante a execução em situações de ensino em sala, o que possibilita experimentar toda a sua funcionalidade.

No desenvolvimento da SD aqui apresentada, procuramos organizar um conjunto de conhecimentos de maneira a facilitar o aprendizado durante a experiência de ensino, tendo como base o que está estabelecido no referencial teórico e os sujeitos da pesquisa, considerando seus conhecimentos prévios e demais atividades desenvolvidas na SD.

Nas fases da experimentação foram aplicadas as atividades da sequência didática, durante sete encontros presenciais, totalizando sete horas-aulas de 50 minutos cada, nas quais o professor (pesquisador) e os alunos desenvolveram as atividades propostas visando a identificação da funcionalidade da SD. Após o desenvolvimento das atividades propostas, foram aplicados testes aos alunos visando verificar a potencialidade da SD na construção do conhecimento científico sobre o tema.

Cada atividade experimental contida na SD se caracteriza pelo que Santos e Souza (2016) denominaram de experimentação ideal. Para isso, o professor busca relacionar os

conhecimentos prévios dos seus alunos com o conteúdo abordado em sala de aula. A realização da atividade prática serve como mecanismo de complementação, interligando todos os tipos de atividade (ilustrativa, investigativa e problematizadora). Ao professor, isso possibilita ensinar e aprender de forma diferenciada e significativa. A experimentação real é aquela que nos deparamos diariamente, não possui nenhum tipo de diálogo e nem é utilizada como ferramenta de promoção de saberes, mas, sim utilizada como demonstração, como atividade extra que exige relatório para definição de uma nota, e que não irá contribuir significativamente para o desenvolvimento científico do aluno (SANTOS e SOUZA, 2016, p. 04). 
A partir dos dados e dos registros dos discursos dos alunos, a Teoria da Aprendizagem Significativa serviu de fundamentação para a prática de ensino, os objetivos do estudo e as questões da pesquisa.

Para investigar o desenvolvimento da aprendizagem dos alunos utilizando a SD foi necessário observar e identificar como ocorreu o progresso cognitivo dos alunos. Para isso, utilizamos para a coleta de dados, considerando, numa abordagem qualitativa: análise dos conhecimentos prévios dos alunos, atividades na SD e análise da avaliação final.

A primeira fase da pesquisa foi a aplicação do questionário inicial, que teve como objetivo identificar os conhecimentos prévios dos alunos e o que eles entendiam sobre o tema polímeros. Essa fase possibilitou identificar os subsunçores que favoreceram a aprendizagem significativa.

Com a finalidade de identificar a evolução conceitual e indícios de aprendizagem significativa, após a aplicação da SD, foi realizada uma análise final a partir das respostas dos alunos ao segundo questionário, que serviu como teste final. Para isso, fez-se necessário que utilizássemos um procedimento de investigação de dados, sendo escolhida a Análise Textual Discursiva (ATD), proposta por Moraes e Galiazzi (2006). Buscamos analisar dados e informações de cunho qualitativo nas respostas dos alunos.

Para Moraes e Galiazzi (2006, p. 120), esse tipo de método de análise é "(...) uma ferramenta aberta, exigindo dos usuários aprender a conviver com a abordagem que exige constantemente a (re)construção de caminhos". Ou seja, a análise textual discursiva considera um movimento contínuo de idas e vindas ao objeto de estudo, que possibilita deduzir o que o aluno escreveu sobre as concepções conceituais envolvidas na pesquisa.

Neste trabalho, com a análise do discurso dos alunos na aplicação da SD, buscou-se identificar, dos dados contidos nos textos, o que poderia se relacionar com o referencial teórico utilizado na sua construção. Lembrando que, conforme Moraes (2003), a partir do momento em que se inicia a leitura, já está ocorrendo uma interpretação, e leitura pressupõe vários significados. Quando o pesquisador realiza sucessivas leituras, ele elabora várias interpretações, atribuindo mais significados ao texto a partir de seus próprios conhecimentos e teorias.

Após estabelecer relações com os objetos de análise, começamos o processo de categorização, buscando reunir os elementos que se encontravam mais próximos da teoria, para a compreensão dos fenômenos investigados. Embora as categorias não tenham sido definidas a priori, elas foram escolhidas a partir da análise dos dados coletados. Cada categoria foi classificada de acordo com os objetivos e com o referencial teórico.

A atividade de número 01 da SD consistiu na realização de um seminário pelos alunos. O método utilizado para a avaliação do seminário foi a observação direta. Segundo Yin (2001), a observação direta é uma metodologia de análise que trata os acontecimentos em tempo real, utilizando os contextos do evento. Os procedimentos deste tipo de método podem ser formais ou informais.

O questionário para análise final teve como objetivo identificar a evolução conceitual dos alunos e verificar indícios de que a SD proposta foi relevante para a aprendizagem significativa deles. Essa análise destacou as vantagens e desvantagens do desenvolvimento das atividades de ensino e aprendizagem por meio da SD.

A atividade final foi composta por duas questões relacionadas com o conteúdo abordado, como na análise prévia; porém, visando investigar a eficiência da SD para a aprendizagem do conteúdo abordado. 
A SD foi aplicada em duas turmas de terceira série do ensino médio de escolas de Sergipe, denominadas como grupo 01 e grupo 02. O grupo 01 foi composto por 17 alunos de uma escola da rede privada de ensino e grupo 02 por 27 alunos de uma escola pública da rede estadual de ensino.

\section{Resultados e Discussões}

Teste inicial

A primeira questão teve como objetivo identificar se os alunos conseguiam conceituar polímeros, a partir da seguinte questão:

Questão 01 - Os polímeros estão entre os materiais mais utilizados no nosso cotidiano. Logo, temos contato diário com eles mesmo sem percebermos. Para você, o que são polímeros?

A partir das respostas, foi possível notar que 12 alunos do grupo 01 e 11 do grupo 02 relacionaram o conceito de polímeros com os plásticos; apenas um aluno do grupo 01 e quatro alunos do grupo 02 relacionaram com macromoléculas. Com isso, tem-se que a maioria deles, de forma correta, relacionou polímeros com os plásticos, que são materiais com os quais eles têm um contato maior no cotidiano. Esses alunos justificam suas ideias por meio de expressões como: "são substâncias capazes de resistir a alta pressão, geralmente relacionados a plásticos"; "são compostos geralmente feitos de plásticos que é o polímero mais abundante, que possui várias classes, do mais resistente ao mas flexível"; "um tipo ou todo tipo de plástico"; "são várias unidades idênticas de macromoléculas aglomeradas"; "são pequenas partículas que se juntam para formar um polímero" e " são unidades de macromoléculas que quando se juntam formam o plástico."

As justificativas apresentadas por 11 alunos do grupo 01 e por 20 alunos do grupo 02 demostraram o que Ausubel (2003, p.10) constatou em seus estudos: para responder às questões, os alunos utilizam o conhecimento que já possuem, mesmo que embasados no senso comum. A nova aprendizagem de cada indivíduo é influenciada por esse conhecimento presente na sua estrutura cognitiva.

Para a questão 02, transcrita a seguir, pedimos aos alunos para exemplificarem alguns tipos de polímeros, relacionados aos conceitos expostos na questão 01.

Questão 02 - Com o passar dos anos, utilizar polímeros virou uma necessidade tanto nas indústrias como nas atividades que realizamos em nossa casa. Cite alguns materiais que você considera que são compostos de polímeros.

Nas respostas a esse questionamento, notamos que material mais citado foi o que compõem as garrafas plásticas tipo pet, que é o derivado de politeraftalato de etileno. Acrílico e PVC foram também citados, mas somente por uma minoria. Provavelmente, as garrafas pet se encontram mais presentes no cotidiano desses alunos, sendo também abordadas como lixo que traz problemas ambientais.

$\mathrm{Na}$ questão 03 o objetivo foi verificar as concepções dos alunos sobre os tipos de reações químicas envolvidas na fabricação de polímeros. 
Questão 03 - Para se obter um produto polimérico, os reagentes envolvidos passam por um conjunto de reações químicas. Você conhece alguma reação química envolvida na fabricação de um polímero? Em caso positivo, cite-a.

Quatro alunos do grupo 01 e três do grupo 02 disseram conhecer alguma reação química envolvida no processo de fabricação de polímeros, e apenas um do grupo 01 e dois do grupo 02 responderam corretamente, como: "reação de poliadição". Os outros associaram a reações já estudadas em outros assuntos da química, mas não se aplicando de forma direta às reações poliméricas, como: "combustão e formação", "reação de combustão ou processo de queima que resulta em $\mathrm{CO}_{2}+\mathrm{H}_{2} \mathrm{O}$ ". Apenas um dos alunos do grupo 02 justificou não conhecer, mas demonstrou ter ideia de que seria uma reação de adição: "Acho que tem reações térmicas, adição de outros elementos."

Como já foi discutido anteriormente, as justificativas dos alunos expressam a aprendizagem deles vinculada a conhecimentos científicos que já se encontravam no sistema cognitivo e às experiências já vividas por eles, que possibilitaram a aprendizagem de conceitos equivocados sobre polímeros.

A questão 04 teve como objetivo investigar se os alunos conheciam a matéria prima utilizada na fabricação dos polímeros.

Questão 04 - Todo produto deriva de matéria-prima. Você sabe qual é a principal matéria-prima dos polímeros? Caso sim, cite-a.

No grupo 01, 11 alunos afirmaram conhecer a matéria-prima utilizada na fabricação de polímeros, e no grupo 02, 14. As matérias-primas empregadas na fabricação desses compostos, citadas pelos alunos que afirmaram ter conhecimento desse material foram: "petróleo", "látex", "metano", "plásticos" e "carboidrato". É provável que alguns alunos tenham citado o plástico como sendo o constituidor dos polímeros por sua utilização mais ampla no cotidiano. Outros citaram o petróleo, por se tratar de uma importante fonte de matériaprima para a indústria; o látex por ser a principal matéria-prima na fabricação da borracha, e talvez relacionem o carboidrato com os polímeros essenciais para a vida.

Com a questão 05 se buscou conhecer a opinião dos alunos a respeito dos problemas causados ao meio ambiente pelo uso excessivo de materiais poliméricos.

Questão 05 - Você considera que os polímeros podem ser uma ameaça ao meio ambiente? Explique porquê.

Previa-se que os alunos não teriam dificuldades em responder a esse questionamento, uma vez que assuntos envolvendo riscos ao meio ambiente são comuns no cotidiano escolar. Porém, dois alunos do grupo 01 e 05 do grupo 02 demonstraram acreditar que os polímeros não representam ameaça ao meio ambiente. Além disso, um aluno do grupo 01 e dois do grupo 02 ainda aparentaram indecisão sobre isso quando afirmaram: "Não, pois é um tipo de plástico" (Grupo 01); "Depende da forma que é utilizada, seja prejudicial ou não", e, "Não, pois podem ser reciclados" (Grupo 02). Esses alunos demonstraram entender que os polímeros sozinhos não são uma ameaça ao meio ambiente, pois se forem descartados corretamente ajudariam ao planeta; sendo considerados uma ameaça somente se o indivíduo não tiver consciência da funcionalidade deles. 
A questão 06 possibilitou saber como o tema polímeros já havia sido abordado nas aulas prévias de Química e auxiliou na identificação das concepções dos alunos sobre esse tema.

Questão 6 - Nas aulas que você assistiu da disciplina Química, você lembra se o tema Polímeros foi abordado? Caso você tenha assistido a alguma aula sobre esse conteúdo, apresente o que você lembra.

Conforme as respostas dos alunos, o conteúdo não havia sido abordado com outras finalidades na sala de aula, nem mesmo em apresentações sobre reciclagem. Um dos alunos do Grupo 01 informou que "Na aula não, essa era a primeira a abordar o tema. (Aluno do Grupo 01)".

\section{Sequência Didática}

\section{Primeiro encontro - Conhecendo a história dos polímeros}

A partir da análise dos conhecimentos prévios dos alunos participantes, iniciamos a SD com uma apresentação historiando sobre polímeros, de forma a assegurar que eles conhecessem sobre os principais personagens e acontecimentos precursores do desenvolvimento desses materiais ao longo do tempo. Utilizamos como estratégia de ensino a aula expositiva, com o auxílio de apresentações empregando datashow. Essa parte teve a pretensão de estabelecer conexões significativas entre os conceitos apresentados.

Para verificar a aprendizagem e as dificuldades dos alunos quanto ao entendimento dos conceitos, foi realizada uma atividade de pesquisa sobre o histórico de um determinado polímero. Os alunos foram divididos em equipes menores e cada equipe escolheu um polímero para historiar. Após a escolha, cada equipe expôs oralmente o que pesquisou. Em seguida à apresentação, foi realizada uma discussão sobre cada tema apresentado.

A apresentação na forma de comunicação oral foi escolhida como estratégia por se considerar que traria contribuições para aprendizagem dos alunos, tanto dos que estariam expondo quanto para os ouvintes, além de exigir outas atividades prévias, como pesquisa, planejamento e organização dos dados encontrados, e de promover a discussão em sala de aula. A discussão possibilitaria a interação entre os alunos, sendo considerada um caminho para a aprendizagem, pois envolveria a exposição de pontos de vistas.

Os polímeros abordados pelas equipes do grupo 01 e do grupo 02 foram: policloreto de vinila (PVC), celofane, nylon, politeraftalato de etileno (PET) e polimetilmetacrilato (acrílico). Os critérios utilizados para a avaliação das apresentações foram: abordagem histórica, conceito, domínio de conteúdo abordado, fatos curiosos da história e utilização dos polímeros no Brasil. É importante ressaltar que durante o desenvolvimento da atividade pelas equipes não houve a necessidade de intervenção do professor. As atividades realizadas pelos alunos foram além do requerido, o que demonstra que eles já haviam desenvolvido atividades semelhantes em outras disciplinas, sobre outros temas.

Uma estratégia utilizada para o acompanhamento das atividades foi a observação direta. Segundo Marconi e Lakatos (2002), a observação tem papel fundamental na análise dos dados, porque permite ao investigador estabelecer um contato direto com a realidade estudada, que à primeira vista pode aparentar ser incompreensível.

Para as apresentações, todos os grupos pesquisaram um tipo de polímero que está presente no cotidiano, também procuraram historiar sobre o desenvolvimento do polímero, 
apresentando os principais acontecimentos relacionados ao desenvolvimento dele e ao conceito. Vale ressaltar que a fonte de pesquisa utilizada pelos alunos foi a internet, em sites de história da química. Os alunos do grupo 01 demonstraram conhecer os temas abordados. No grupo 02, uma das equipes não apresentou domínio de conteúdo em comparação às outras. Apenas duas equipes do grupo 01 e uma do grupo 02 comentaram sobre fatos curiosos envolvendo o desenvolvimento dos polímeros abordados. Um dos fatos foi relatado da seguinte forma: "Brandenberg, em 1908, que era químico e engenheiro suiço (1987-1954), trabalhava sentado num restaurante quando um cliente derramou vinho na toalha, ai ele viu que deveria inventar um pano de revestimento impermeável.". Outra equipe comentou que "A bandeira fincada na Lua por Neil Armstrong e o seu traje espacial foram feitos com nylon".

\section{Segundo encontro - Conhecendo os polímeros}

Para identificar a aprendizagem do conteúdo sobre o tema proposto nesse segundo encontro, foi realizada uma atividade experimental com o objetivo de proporcionar aos alunos demonstrações sobre diferenças e semelhanças entre materiais poliméricos com características termoplásticas e termorrígidas.

A atividade consistiu em submeter alguns materiais poliméricos (cano PVC, sacola de supermercado, copo descartável, garrafa plástica, luva cirúrgica entre outros) à chama de uma vela para verificar se houve ou não deformação dos materiais. Em seguida, os materiais foram classificados como termoplásticos ou termofixos e foi realizada análise sobre a semelhança entre os materiais poliméricos envolvidos na prática.

A maioria dos alunos conseguiu identificar se certo polímero era termofixo ou termoplástico a partir da identificação das características observadas no processo de aquecimento do material utilizado. Um aluno do grupo 01 e vinte alunos do 02 não conseguiram identificar quais as condições que levaram o cano de PVC ser um polímero com características termoplásticas. Isso foi decisivo para que mais uma aula ocorresse, de forma a se dispor de um maior tempo para explicações sobre as propriedades dos polímeros e quanto às diferenças básicas entre as características desses materiais.

É importante ressaltar que, embora a sequência apontasse para que o aluno recorresse ao conteúdo contido no livro didático e ao próprio texto da sequência, para as análises eles somente empregaram o conhecimento adquirido na aula expositiva.

\section{Terceiro encontro - Ainda polimerizando}

No terceiro encontro tivemos o intuito de apresentar os principais processos de polimerização, de forma a possibilitar a compreensão deles sobre tais processos. Inicialmente, introduzimos o conceito de reações poliméricas e, em seguida, realizamos uma atividade experimental sobre "Polímero caseiro" para depois explanar sobre os tipos de reações.

Após a explanação dos conteúdos, aplicou-se uma atividade de interpretação da prática com a finalidade de verificar a compreensão dos alunos sobre os conteúdos abordados. Com a questão 01 da atividade 03, relativa à análise dos dados do terceiro encontro da aplicação da SD, procurou-se identificar o produto formado após a mistura das duas soluções resultante da reação de polimerização. 
A atividade experimental consistiu na produção de um polímero caseiro, a partir de cola branca, do tipo utilizada em atividades escolares, bórax, anilina para dar uma coloração desejada ao produto, nesse caso azul e vermelho, além de palitos de picolé.

Questão 01- O que foi possível observar quando se misturam as duas soluções?

Esse quesito requereu dos alunos um conhecimento de outros conteúdos da química, mais especificamente de misturas e reações químicas, para uma melhor compreensão do conteúdo abordado. A atividade experimental foi utilizada como problematização do conteúdo "tipos de reações poliméricas", que poderiam ser reação de polimerização de adição ou reação de polimerização de condensação. Vale ressaltar que para uma melhor compreensão da atividade, foi necessária a intervenção do professor para esclarecer alguns procedimentos.

Observou-se que durante a preparação do material os alunos conseguiram identificar as principais características de uma reação polimérica quando eles afirmavam: "o copo está esquentando", "a mistura vai ganhando consistência e, aos poucos, vai virando algo gelatinoso". A partir dessas justificativas, eles tentaram explicar que estava ocorrendo uma reação, com liberação de calor, formando um novo material, com novas características.

A intenção desta atividade foi a aprendizagem de aspectos do conteúdo por meio de uma situação problema. Buscou-se, com isso, o desenvolvimento de uma experimentação ideal, na qual o professor se utiliza do conteúdo abordado em sala de aula e de atividades práticas do tipo ilustrativas, investigativas e problematizadoras para ensinar e aprender (SANTOS e SOUZA, 2016). Nas atividades investigativas, por exemplo, os estudantes têm oportunidade de argumentar, comunicar resultados, socializar exemplos e aceitar ideias e modelos explicativos mais coerentes do ponto de vista científico (WARTHA e LEMOS, 2016). Tais atividades promovem troca de saberes e formas diferenciadas de aprendizagem.

A segunda questão desta atividade foi a seguinte:

Questão 02 - Que tipo de material foi formado com a junção das duas soluções?

Ao analisarmos as respostas à questão 02, identificamos que oito dos alunos do grupo 01 e treze do grupo 02 identificaram o resultado do experimento como um material gelatinoso, com características elásticas. Outros identificaram como um material sólido, pois o líquido que havia no recipiente não se misturou com o material formado. A partir das respostas do grupo 01, notamos que sete dos alunos afirmaram ter sido formado um material semelhante à geleia. Somente um aluno relacionou o material formado ao silicone, pelas características apresentadas, e quatro afirmaram sobre a formação de um material sólido. As justificativas desses alunos estão corretas, pois a geleia formada também é um material sólido. No grupo 02, observamos que treze dos alunos se referiram ao produto formado como sendo material gelatinoso; cinco deles relacionaram com massa elástica; e nove com um polímero termoplástico. No grupo 02, notamos que nove dos 27 alunos investigados demostraram uma evolução conceitual, com assimilação do conteúdo abordado. Tal evolução pode ser exemplificada na fala de dois deles: "formou-se um polímero termoplástico"; "um polímero aparentemente termoplástico, pois adquire formas ao ser manuseado" 
A terceira questão da atividade 03 , relativa à atividade do terceiro encontro da aplicação da SD foi:

Questão 03 - Após a observação do produto formado, informe que tipos de materiais semelhantes a esses existem em nosso cotidiano?

Buscamos identificar nas respostas dos alunos se eles reconheciam no cotidiano algum material semelhante ao produto formado na atividade, a partir de dados sobre o nível de compreensão e de assimilação do conteúdo já abordado; além de indicar a presença desses polímeros no cotidiano dos alunos. A assimilação de conceitos estabelece na estrutura cognitiva do aluno uma relação de modo substantivo, ou seja, eles adquirem novos conceitos pela relação com as ideias já existentes na sua estrutura cognitiva (MOREIRA, 2009).

Sete alunos do grupo 01 e vinte do grupo 02 relacionaram o produto do experimento com a amoeba; dois do grupo 01 e sete do grupo 02 relacionaram com a geleinha. Essas duas denominações representam um mesmo produto. A amoeba, é um polímero formado pela reticulação do álcool polivinílico, produto presente na cola branca, com um composto de boro. Um brinquedo composto por esse material se fez presente na infância de muito dos alunos e até hoje é vendido em lojas de brinquedos.

\section{Quarto encontro - Aplicações dos polímeros no cotidiano}

Nesse quarto encontro, o objetivo foi introduzir conceitos da química do poliuretano a partir da problematização, visando a utilização por parte dos alunos do maior número de subsunçores, com a finalidade de se ter um olhar mais detalhado do conhecimento já adquirido por eles.

Iniciamos esse encontro com a leitura do texto intitulado "Sexo seguro com poliuretano" (SOUZA, 2010). O texto aborda sobre algumas aplicações do poliuretano no cotidiano, tendo sido utilizado como um organizador prévio, com o objetivo de estabelecer uma ligação entre o conhecimento geral sobre polímeros e conhecimentos mais específicos sobre poliuretano. Após a leitura do texto ocorreu uma breve discussão sobre o conteúdo abordado; em seguida, demos início à abordagem do conteúdo poliuretano.

Em uma aula expositiva foi apresentado um breve relato histórico sobre o desenvolvimento de poliuretanos, abordando conceito, características, aplicações, além das vantagens e desvantagens da sua utilização. Para fazer a verificação da aprendizagem do conteúdo, utilizamos uma atividade experimental para demonstrar a reação de síntese que ocorre com esse tipo de polímero, que resulta em espuma, conhecida como espuma PU (espuma de poliuretano). Em seguida, foi proposta uma atividade a respeito da experimentação utilizada para análise dos dados. Após a atividade, os alunos responderam ao seguinte questionamento:

Questão 01 - O que foi produzido com a junção dos dois reagentes, diisocianato e poliol?

Observamos que todos os alunos do Grupo 01 e do Grupo 02 identificaram corretamente o tipo de material formado. Isso demonstra que eles conseguiram compreender o que estava sendo abordado nas aulas expositivas e demostraram uma evolução significativa do conhecimento sobre o tema. Algumas das respostas: "espuma", 
"uma espuma dura e que se expande com a junção dos elementos", "formou-se uma espuma homogênea e logo depois endureceu" e, "uma espuma que é utilizada na geladeira".

$\mathrm{Na}$ questão 02 da atividade foi indagado aos alunos que tipo de reação ocorreu com a junção desses dois reagentes. Os alunos do grupo 01 e do grupo 02 identificaram corretamente o tipo de reação envolvida no processo de produção da espuma poliuretânica, que, nesse caso, trata-se de uma reação de adição.

A questão 03 foi: Durante o procedimento experimental, que características levou você a perceber que estava ocorrendo uma reação?

Todos os alunos do grupo 01 e do grupo 02 relataram que a partir da adição dos reagentes a homogeneização foi iniciada, pois a mistura começou a esquentar o recipiente e a se expandir. Eles, mais uma vez, não conseguiram utilizar termos científicos para justificar o questionamento; provavelmente, por não participarem frequentemente de atividades em que fosse empregada tal linguagem científica. Os termos utilizados foram os do cotidiano, que remetem ao senso comum: "começou a esquentar e logo começou a subir", "após a mistura começar a entrar em ponto de creme e começar a se expandir", "o copo esquentou, a matéria inchou rapidamente deixando o material resistente", "a mudança de um estado para o outro ao decorrer da mistura", "houve uma reação entre os compostos fazendo com que ficasse quente e fosse aumentando o tamanho", e "aquecimento do recipiente e mudança da textura". Essas justificativas demonstram que ocorreu evolução conceitual a respeito do conteúdo abordado, o que nos levou a acreditar que houve aprendizagem sobre o experimento.

A questão 04 serviu para saber a opinião dos alunos sobre a utilização de atividades experimentais nas aulas sobre o tema Polímeros. Buscamos conhecer como os alunos se sentiram ao realizar atividades envolvendo conteúdo científico, trabalho coletivo, discussão de resultados e manuseio do próprio material empregado nas atividades. Conforme os comentários, notamos um grande entusiasmo deles por participarem de atividades que consideraram diferenciadas.

Na questão 05 foi pedido aos alunos que citassem uma aplicação ou utilização no cotidiano do material formado. Essa indagação teve por finalidade propor aos alunos que relacionassem o produto formado com materiais do cotidiano deles. Esse tipo de questionamento auxiliou na análise de como eles estavam aprendendo o conteúdo.

Dentre os materiais relacionados pelos alunos, apenas a boia conhecida como macarrão de piscina não é feita de poliuretano. A matéria prima desse tipo de boia é o polietileno expandido de células fechadas. Mas, devido às características físicas do material, que se assemelham ao poliuretano, os alunos se confundiram no momento de fazer as relações.

\section{Quinto encontro - Reciclagem, Meio Ambiente e CTSA}

Neste encontro buscamos enfatizar a importância da reciclagem de materiais sólidos para o meio ambiente, como forma de auxiliar na conscientização dos alunos e de buscar um ensino com enfoque em ciência, tecnologia, sociedade e ambiente (CTSA).

Iniciamos com uma situação problema a partir da visualização de uma imagem em que se vê o planeta Terra cercado por vasilhames plásticos, como em meio a um lixão (Figura 1). A ideia era retratar os pontos negativos do descarte incorreto dos materiais poliméricos. Após a exibição da imagem, os alunos responderam a duas questões relacionadas ao conteúdo aprendido e à imagem apresentada. 


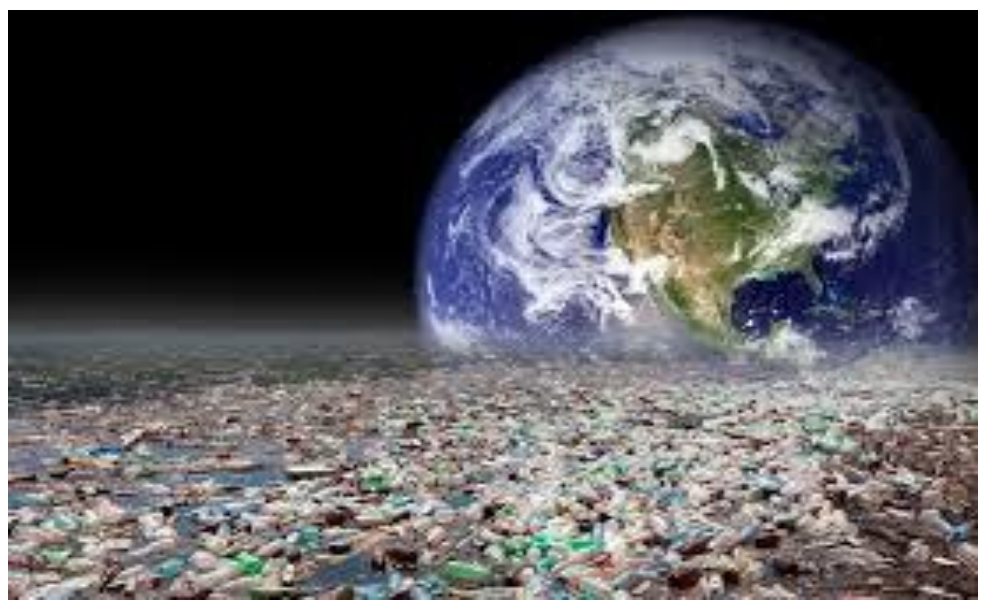

Figura 1. Planeta Terra imerso em polímeros (fonte: site surfinssantos.com.br)

Na primeira questão, como forma de aguçar a interpretação dos alunos, foi pedido que eles dessem um título à imagem apresentada. Na escolha dos títulos, todos eles demonstraram ter conhecimento de que o uso inadequado dos polímeros pode afetar negativamente o planeta Terra. Por exemplo, um dos alunos utilizou a sigla PET e fez uma derivação para formar o tema "Progressão Estrutural Transformadora". Esse tema nos remete à importância da assimilação dos conteúdos aprendidos no cotidiano, já que a imagem traz uma grande quantidade de garrafa plásticas jogada no mar. Observou-se também que todos os alunos relacionaram a imagem com uma característica negativa dos polímeros, associada ao descarte incorreto e à poluição.

Na segunda questão foi pedido aos alunos para relacionar a imagem com o conteúdo abordado. Nas respostas, foi possível verificar a aplicação dos conteúdos já abordados nos encontros anteriores. Isso também confirma a evolução de conceitos gerados ao longo do desenvolvimento da SD, caracterizando a aprendizagem dos alunos sobre o conteúdo abordado. Na análise, observamos que cinco alunos do grupo 01 e quatro do grupo 02 relacionaram a imagem com o conteúdo "Tipos de polímeros" e com o tema "Descarte de polímeros", que foram discutidos na sequência. Os demais alunos associaram ao uso amplo e até exagerado dos plásticos na atualidade.

\section{Sexto encontro - Produção final}

A análise final foi aplicada aos dois grupos de alunos participantes da pesquisa com a finalidade de identificar se o conteúdo foi aprendido de forma significativa por eles. Esse momento foi iniciado com um texto problematizador, intitulado "A importância dos polímeros em sua vida" (DOW, 2015), que aborda a influência de polímeros na composição de produtos de beleza. Embora este texto seja de divulgação de uma empresa comercial, não se deu ênfase a tal fato na atividade.

Na questão 01 da atividade foi pedido que, considerando os conhecimentos adquiridos ao longo das aulas, eles descrevessem em três palavras ou expressões o que são polímeros. Isso foi sugerido com a finalidade de se observar o quanto foi significativa a aprendizagem sobre o tema.

Os três termos que foram usados na definição de polímeros pelos alunos do grupo 01 foram: Composição dos plásticos; Utilidades e cotidiano; e Reciclagem. Com relação aos do grupo 02, as expressões usadas para definir o conteúdo ao longo do desenvolvimento das 
atividades se voltaram mais para os conceitos aprendidos, além das utilidades e aplicações, como: "macromoléculas, termoplástico e termofixo"; "rígidos, borracha e polimerização"; "utilidade, reciclagem e poluição"; e "unidades semelhantes, náilon e fibras". Cada expressão nos revelou os conteúdos que se encontravam implícitos e que auxiliaram na aprendizagem de conteúdos mais relevantes nas estruturas cognitivas dos alunos. Essas expressões se conectam, também, com o quinto saber relatado por Morin (2000), que está relacionado às incertezas. Afinal, o grande número de informações voltadas para o mundo da ciência leva o aluno a questionar sobre a função do conhecimento científico, e isso explica alunos confusos com relação ao conceito de polímeros.

$\mathrm{Na}$ questão 02 foi proposto que os alunos descrevessem o conceito de polímeros e suas aplicações no cotidiano. Nessa parte da atividade buscamos, a partir dos textos escritos pelos alunos, informações que nos mostrassem as concepções conceituais acerca do conteúdo de polímeros. Isso esteve pautado em Ribeiro (2015, p. 72), quando afirma que "toda mensagem escrita está repleta de informações sobre a evolução conceitual do tema e as concepções do aluno".

Observou-se nas respostas da maioria dos alunos que eles souberam explicar o conceito de polímeros, enfatizando as características desses materiais, incluindo classificação, tipos de reações que os produzem e aplicações no cotidiano. Eles também apresentaram informações relativas a danos ao meio ambiente que podem ser ocasionados pelo descarte desses materiais. As respostas nos levaram a concluir que ocorreu a aprendizagem significativa do conteúdo apresentado.

Quatro alunos do grupo 01 e cinco do grupo 02 não souberam explicar o conceito de polímeros. Isso pode ter sido ocasionado pela falta de subsunçores. Essa lacuna pode influenciar significativamente a aprendizagem da informação e sua consequente sedimentação na estrutura cognitiva do aluno. Isso ficou evidente nesses alunos, mesmo com o professor auxiliando nas etapas da aprendizagem. Mas treze alunos do grupo 01 e 22 do grupo 02 conseguiram explicar de forma que fosse possível identificar uma evolução de conceitos, como pode ser verificado em algumas das respostas:

"São compostos formados por cadeias de macromoléculas, cadeias longas, também podem ser remoldados. São classificados em: termoplástico (fácil moldagem), podemos citar as garrafas plásticas, ou termofixos (não podem ser moldados); a exemplo, citamos o cabo de frigideira."

"Sabe-se que polímeros são macromoléculas unidas através de ligações covalentes e que cada molécula é chamada de monômero. Quando os monômeros possuem compostos iguais são chamados de homopolímero, já com compostos diferentes, copolímeros. Existem os polímeros naturais, que são encontrados na natureza, como as proteínas e o látex, e os polímeros artificiais, que são produzidos pelo homem, como o PVC, isopor, teflon, PVA e outros. Os polímeros são classificados em termofixos, que não podem ser remoldados sob calor, e termoplásticos, que podem ser moldados sob determinada temperatura."

"Polímeros são macromoléculas formadas a partir de unidades estruturais menores, os monômeros. Os monômeros de baixa massa molecular os quais a partir das reações de polimerização vem a macromolécula polimérica. Os polímeros são muito usados, em países desenvolvidos 
chega a ser utilizado cerca de 150 quilogramas por habitante. Os polímeros são os nossos plásticos do dia-a-dia, as nossas roupas, os utensílios, sendo o mais usado o polietileno, por ser mais barato. A única desvantagem dos polímeros é a poluição e o seu tempo de decomposição."

Comparando-se os resultados do teste final com o do questionário inicial, entende-se que a sequência de atividades presentes na SD trouxe indícios de aprendizagem significativa para a construção de conceitos do conteúdo de Polímeros.

\section{Conclusões}

Os resultados do estudo nos permitem concluir que os alunos de ambas as classes observadas evoluíram numa mesma perspectiva durante a aplicação da sequência didática que abordou o tema Polímeros em aulas de química.

Com relação às estratégias utilizadas, os resultados demonstraram terem sido motivadoras, servindo como organizadores prévios para os subsunçores. À medida que os subsunçores se tornaram mais elaborados, foi possível aos alunos compreender informações novas e aprender significativamente.

Quanto às dificuldades conceituais dos alunos, concluiu-se que não estavam relacionadas exclusivamente ao conteúdo Polímeros, uma vez que eles demonstraram ter adquirido novos conhecimentos sobre conceitos e quanto às características do tema em questão, mas nem sempre foram capazes de relacioná-los corretamente.

A utilização de experimentos e a leitura de textos serviram de instrumentos cognitivos que possibilitaram relações entre os subsunçores e o novo conceito aprendido. As análises demonstraram que as situações-problema utilizadas no estudo auxiliaram relações úteis entre os novos conhecimentos e os conhecimentos prévios nas estruturas cognitivas dos alunos. Nesse contexto, podemos considerar que as atividades da SD se relacionaram com os conteúdos já existentes nas estruturas cognitivas deles.

A utilização de várias estratégias que promovam modificações na forma de ensinar, possibilitam oportunidades para novas configurações de ensino e de aprendizagem, criando variadas relações entre as SD e as estruturas cognitivas dos alunos, o que representa uma característica da aprendizagem significativa.

A combinação de metodologias e a interdisciplinaridade, como forma de organização do trabalho pedagógico sobre esse conteúdo, permite a formação de saberes sobre a área do conhecimento em que se insere esse conteúdo.

\section{Referências}

AMARAL, L. Trabalhos práticos de química. São Paulo: Nobel, 1996

AUSUBEL, D.P. Aquisição e retenção de conhecimentos: uma perspectiva cognitiva. $2^{a}$ ed. Coimbra: Platano Edições Técnicas, 2003.

BALDISSERA, A. Pesquisa-ação: uma metodologia do "conhecer" e do "agir" coletivo. Sociedade em Debate, v. 7, n.2, p. 5-25, 2001. 
BRASIL. Ministério da Educação - MEC, Secretaria de Educação Média e Tecnológica Semtec. PCN + Ensino Médio: orientações educacionais complementares aos Parâmetros Curriculares Nacionais - Ciências da Natureza, Matemática e suas Tecnologias. Brasília: MEC/Semtec, 2002.

BRASIL. Ministério da Educação. Secretária de Educação Básica. Orientações Curriculares para o Ensino Médio: Ciências da Natureza, Matemática e suas Tecnologias. Brasília, 2006.

CHASSOT, A. Para que(m) é útil o ensino? 2.ed. Canoas: Ed. ULBRA, 2004.

DOW, 2015. <http://www.dow.com/brasil/empresa/discover-dow.htm>. Acessado em: 25/02/2017.

HAGE JUNIOR, E. Aspectos históricos sobre o desenvolvimento da ciência e tecnologia de polímeros. Revista Polímeros: Ciência e Tecnologia. São Carlos, v. 8, n. 2, p. 6-9, 1998.

MORIN, E. Os sete saberes necessários à educação do futuro. 2ª ed. Brasília: Cortez, 2000.

MARCONI, M. A.; LAKATOS, E. M. Técnicas de Pesquisa. $5^{a}$ ed. São Paulo: Atlas, 2002.

MILARÉ, T.; RICHETTI, G. P.; ALVES FILHO, J. P. Alfabetização científica no ensino médio: Uma análise dos temas da seção química e sociedade da revista química nova na escola. Química Nova na Escola, v. 31, n. 3, p. 165-171, 2009.

MORAES, R. Uma tempestade de luz: a compreensão possibilitada pela análise textual discursiva. Ciência \& Educação, v.9, n. 2, p. 191 - 211, 2003.

MORAES, R.; GALIAZZI, M. C. Análise Textual Discursiva. ljuí: Ed. Unijuí, 2006.

MOREIRA, M.A. Aprendizagem significativa: da visão clássica à visão crítica. In: Anais do V Encontro Internacional sobre Aprendizagem Significativa, Madrid. p. 1-15, 2006.

MOREIRA, M. A. Negociação de significados e aprendizagem significativa. Ensino, Saúde e Ambiente, v. 1, n. 2, p. 2-13, 2008.

MOREIRA, M. A. Subsídios teóricos para o professor pesquisador em ensino de ciências: A teoria da aprendizagem significativa. $1^{a}$ ed. Porto Alegre: não informado, 2009, (compilação de trabalhos publicados).

MOREIRA, M. A.; MASINI, E. F. S. Aprendizagem Significativa: a teoria da David Ausubel. $2^{a}$ Ed., São Paulo: Ed. Centauro, 2006.

NOVAK, J. D.; GOWIN, D. B. Aprender a aprender. Lisboa: Plátano Edições Técnicas. 1996, Tradução ao português, de Carla Valadares.

RIBEIRO, T. N. O ensino de razões trigonométricas no triângulo retângulos a partir de situações aplicadas à Física: Um estudo baseado nas unidades de ensino potencialmente significativas (UEPS). Tese de doutorado. Universidade Anhanguera de São Paulo, 2015.

SANTOS, B. F. Ensino de Química em diferentes contextos sociais. Amazônia: Revista de Educação em Ciências e Matemática, v. 13, n. 28, p. 104-118, 2017.

SANTOS, G. G.; SOUZA, D. N. Experimentação real versus experimentação ideal no ensino de ciências e a prática do pensamento crítico. Scientia Plena, v. 12, p. 1-11, 2016. 
SOUZA, L. A. "Sexo seguro com poliuretano"; Brasil Escola. Disponível em <http://brasilescola.uol.com.br/quimica/sexo-seguro-com-poliuretano.htm>. Acesso em 17 de abril de 2016.

WARTHA, E. J.; LEMOS, M. M. Abordagens investigativas no ensino de Química: limites e possibilidades. Amazônia: Revista de Educação em Ciências e Matemática, v. 12, n. 24, p. 0513, 2016.

YIN, R. K. Estudo de caso: planejamento e métodos. Porto Alegre: Bookman, 2001. 